\title{
The thread of space, time and event: An implication in media studies
}

-- Krishna Poudel

\section{Introduction}

Recently widely circulated publications, the World Development Report 2009 of the World Bank (WB) and Human Development Report 2007/2008 of the United Nations Development Programmes (UNDP), have strongly emphasized the geographical space of the world. The World Development Report 2009 has a sub-title 'reshaping the economic geography', whereas the Human Development Report has dealt on 'fighting climate change, human solidarity in a divided world'. Both these documents have tried to disseminate a clear message about the interrelationship of geographical space and the human and natural processes, with special reference to functions and events associated in the contemporary world.

The space is usually characterized by its elements of dimensionality, continuity, proximity and separation (NRC, 2006). Dimensions are components of a coordinate grid typically used to locate a point, line or area in a certain defined 'space' as, for example, on the globe by latitude, longitude and elevation ( $\mathrm{X}, \mathrm{Y}$ and $\mathrm{Z}$ ). In space-time, a coordinate grid that spans the $3+1$ dimensions locates 'events' (rather than just points in space), so time is added as another dimension to the grid, and another axis. This way, it is possible to plot where and when something is. Unlike in normal spatial coordinates, there are restrictions for how measurements can be made spatially and temporally. This is closely associated with the representation of events in the contextual ground of space and time. The representations can be made in a variety of modes and media (graphic [text, image or maps, and video], tactile, auditory, kinesthetic, and olfactory) to describe, explain, and communicate about the structure, operation, and function of objects and their relationships. Spatial thinking is not restricted to any domain of knowledge (NRC 2006).

Bodhi, 3 (1), 92-98. ISSN 2091-0479. (C) 2009 Kathmandu University 


\section{Crux of the issues}

All physical events take place on space and time dimension. Event is the end result in a thread or string of space-time. What (event type) and when (time) are closely interlinked on where (space) that indicates the geographical location. In a classical trend of media professionals usually emphasis has been given in recording and reporting events however, usually put least priority on mentioning spatial dimensionality. Space on the globe refers its permanent reference point. Event usually gives its happenings in a time dimension which is dynamic.

Event and time can have a linkage with the space which is static on its locational standpoint. Illustration of major events of the world can be linked with its space to understand the historical past. The civilization of Mesopotamia, Roman, Ganga and Indus River Valley all give us the factual recording of the then human, cultural and scientific development. The historical archives of major events can be explored by excavation of cultural sites. How to operate these activities in future unless we record the existing events in spatial dimension? The spatial dimension can be performed by searching the answer of questions in regarding to geographical events. What, where, when, how, why and what if are some of the interrogative terms helps us to handle the thread of space, time and event.

Space can be marked by absolute referencing system based on the global coordinate lines. Spatial thinking is a collection of cognitive skills (NRC 2006). According to D. Montello (1997) spatial knowledge develops in humans through three progressive stages: landmark, route and survey knowledge. The first refers to the capacity of memorizing places in relation to an event, and the second, to developing the sense of ordered sequences of landmarks. The last and more progressed stage is where the knowledge simultaneously embraces more locations, their interrelations and allows for detouring, shortcutting and creative navigation. The skills consist of declarative and perceptual forms of knowledge and some cognitive operations that can be used to transform, combine, or otherwise operate on Bodhi, 3 (1), 92-98. ISSN 2091-0479. (C) 2009 Kathmandu University 
this knowledge. The key to spatial thinking is a constructive amalgam of three elements: concepts of space, tools of representation, and processes of reasoning (NRC 2006).

\section{Referencing system}

Referencing space, time and event is a challenge. Several different recoding systems can be applied. However, the recently developed GI science and technology helps us to handle the geo-reference, time reference and attribute reference data more easily. In fact the event can be treated as attribute of space and time and which can be mapped in a two dimensional analog or digital format. It can be displayed with color illustration with full text of information in an attractive way.

Geographical Information Systems (GIS) were devised in the $1960 \mathrm{~s}$ as computer applications for handling volumes of information obtained from maps as well as for performing operations that would otherwise be too tedious, expensive, or inaccurate to perform by hand (Aronoff 1989; Peuquet and Marble 1990:50). Recent trends have been toward the development of GI Science and Technology (Goodchild 2004:710). GIS, Remote Sensing (RS) and Global Positioning Systems (GPS) are jointly operating in a single sphere of GI science and technology also called ' 3 -S' systems (Deichmann and Wood 2005).

The last decade witnessed an unprecedented growth and development in earth observation data and applications. Earth observation techniques through remote sensing are proving to be more cost effective than ground-based techniques over large areas. RS data have the benefits of the synoptic view of a large area, which helps in obtaining the proverbial 'bird's eye-view' of the features, especially of inaccessible geographic terrain. Furthermore, there has been an emergence of high-resolution satellite data in recent years, with greater degree of spatial and temporal variations than ever before. Similarly, GPS technology provides the ability to compute and capture position

Bodhi, 3 (1), 92-98. ISSN 2091-0479. (C) 2009 Kathmandu University 
anywhere on the earth's surface with 24-hour coverage. Systems like Google Earth and Microsoft Virtual World have revolutionized the way we access and visualize satellite-based information seamlessly from local to global levels with unprecedented level of details.

Advances in information and communication technology combined with earth observation technology and geographical analysis and modeling tools are now available to quantify, model, document, and disseminate information on key socioeconomic, environmental, and natural resources conditions and trends. This convergence of information technology (computers, databases, software, networks, especially the Internet), and space science technology (remote sensing, global positioning system, light detection and ranging (LiDAR) have provided effective and promising tools and methods for dealing with diverse issues. Geo-Information (GI) Systems have emerged as powerful tools in integrating and analyzing information from divergent sources and presenting the results in an effective and efficient way. These factors have led to the creation of a suitable context of events enabled to depict where and when more specifically in an understandable style for wider circulation.

\section{Methods of referencing}

With a view to refer the space in event recording purpose it can be referred from micro to macro spatial referencing system. What and where mapping generally carry the notion of general naming convention usually adopted in the local language and tradition. Local name of the point of event occurrence either with reference to village, Tole or community immediately could follow the ward number of the Village Development Committee (VDC) or Municipality and the district. This system of referencing enabled to give the relative position of the place of event occurrence as well as the pro-forma of the event in a convincing way (Fig. 1).

Bodhi, 3 (1), 92-98. ISSN 2091-0479. (C) 2009 Kathmandu University 


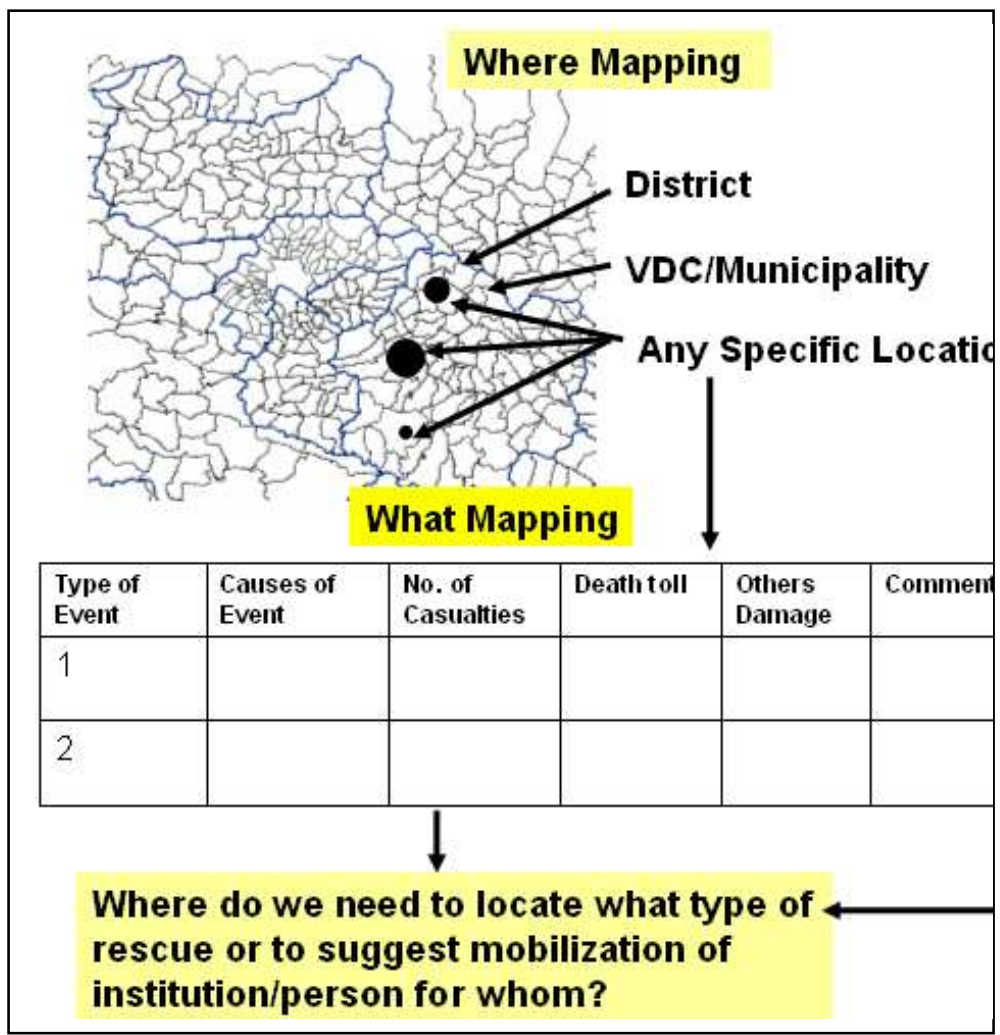

Figure 1: Pro-forma of the event recording in a georeferencing system

In the mean time, a step ahead from the reference system Global Positioning System (GPS) device also can be used to entertain more specific absolute geo-reference in two dimensional Cartesian system i.e. Latitude, Longitude and altitude of particular location in a global referencing system. Handling GPS is more appropriate for the media professionals to save time and other terrain inaccessibility. It also could assure security menace by providing direction and live update on route tracking system (Fig. 2).

Bodhi, 3 (1), 92-98. ISSN 2091-0479. (C) 2009 Kathmandu University 


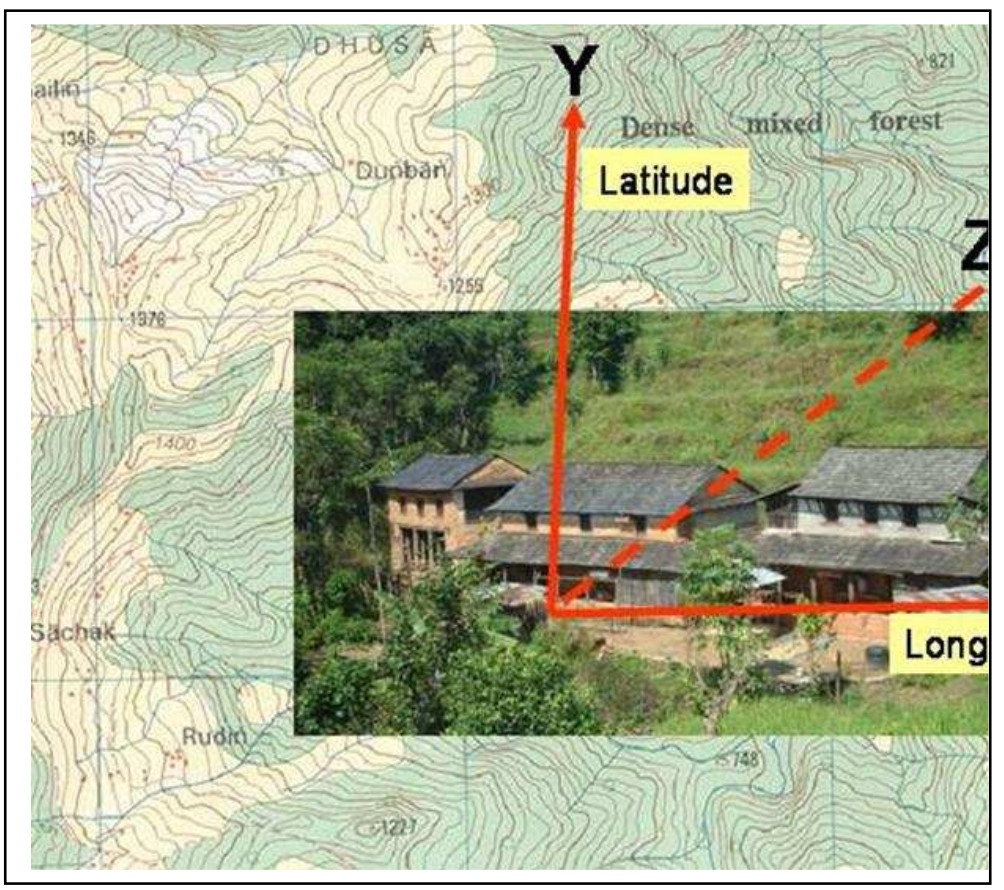

Figure 2: Tracking the location of event by applying GPS device. Topographical map, photographs and GPS all can be used for the event recording in a geo-referenced system.

\section{Conclusion}

Space, time and event have close linkages, and hence they are to be considered as components of a thread. Media professionals are usually supposed to highlight the event and have to entertain all elements of the thread. Space and time give 3-D information and the event adds plus one. Understanding spatial elements and characteristics supports the validation of event. Also, it carries the significance for the historical evidences of record and future investigation. For this purpose GIS, Remote Sensing and GPS are to be incorporated in the curriculum of media studies to

Bodhi, 3 (1), 92-98. ISSN 2091-0479. (C) 2009 Kathmandu University 
make acquainted with space, time and event or in a single word 'spatial thinking'.

\section{References}

Aronoff, S. (1989). Geographic information system: A management perspective. Ottawa: WDL Publishers.

Deichmann, U., and Wood, S. (2005). GIS, GPS and remote sensing. Retrieved November 21, 2009 from http://www.iapad.org/publications/ppgis/gis_gps_and_r emote_sensing.pdf.

Goodchild, M. F. (2004). GIScience, geography, form, and process. Annals of the Association of American Geographers, 94(4), 709-714.

Montello, D. (1997). NCGIA Core Curriculum in GIS. National Center for Geographic Information and Analysis, University of California, Santa Barbara.

NRC. (2006). Learning to think spatially: GIS as a support system in the K-12 curriculum. Washington DC:

National Research Council, National Academic of Sciences, The Academies Press.

Peuquet, D. J., and Marble, D. F. (1990). What is a geographic information system? In D. J. Peuquet and M. F. Duane (Eds.). Introductory reading in GIS (pp. 1-7). New York: Taylor and Francis.

UNDP. (2007). Human development report 2007/2008, fighting climate change: human solidarity in a divided world. New York: UNDP.

The World Bank. (2009). World development report 2009:

Reshaping economic geography. Washington, DC: The World Bank.

Bodhi, 3 (1), 92-98. ISSN 2091-0479. (C) 2009 Kathmandu University 